\title{
Stenting as a palliative method in the management of advanced squamous cell carcinoma of the oesophagus and gastro-oesophageal junction
}

\author{
Janusz Wlodarczyk ${ }^{1,2}$, Jarosław Kużdżał ${ }^{1,2}$ \\ ${ }^{1}$ Department of Thoracic and Surgical Oncology, John Paul II Hospital, Krakow, Poland \\ ${ }^{2}$ Department of Thoracic and Surgical Oncology, Jagiellonian University Medical College, Krakow, Poland
}

Videosurgery Miniinv 2016; 11 (1): 1-8 DOI: 10.5114/wiitm.2016.58979

\begin{abstract}
Advanced squamous cell carcinoma of the oesophagus and gastroesophageal junction usually requires palliative treatment, and the method of choice is stenting. There are several types of stents currently available, including: self-expandable metallic stents (fully or partially covered); self-expandable plastic stents; biodegradable stents. Each of the mentioned stents has its advantages and limitations, and requires a proper, patient-tailored selection. Due to the close anatomical relationship between the oesophagus and bronchial tree, some patients may require bilateral stenting. Oesophageal stenting may not only be considered as a palliative procedure, but can also be implemented to alleviate dysphagia during preoperative chemotherapy and/or radiotherapy.
\end{abstract}

Key words: dysphagia, oesophageal cancer, stenting, oesophageal fistula.

\section{Introduction}

Squamous cell carcinoma of the oesophagus is the fourth cause of death in males and seventeenth in females. There has been no change or a slight decrease in incidence over the last three decades, unlike gastro-oesophageal junction carcinoma, which exhibits a constant increase in incidence [1-5]. The development of squamous cell carcinoma of the oesophagus and gastro-oesophageal junction leads to dysphagia. More than $50 \%$ of patients present with an unresectable tumour, and progressive weight loss and dysphagia require palliative treatment. Among the many available methods of palliation, stenting, laser therapy, chemoradiation, and photodynamic therapy should be considered. However, stenting is the method of choice [6-8]. This is because of its technical simplicity, wide availability and immediate alleviation of dysphagia.
For the first time, in 1885 , the prototype of the stent was used for intubation of the strictured oesophagus, and rapid development of stenting was observed with the development of modern endoscopy [9]. In the 1970s and 1980s, rigid, semi-rigid and plastic stents were used (Photos 1 and 2), associated with a high percentage of complications, such as perforation, stent migration, and mortality [10]. The introduction of self-expanding metallic stents enabled their safe and widespread use. Domschke et al. used such a stent for the first time in 1990 [11]. In 1991, the modified, silicone-covered Gianturco expandable metallic stent was introduced by Song et al. [12].

The aim of the present study is to analyse the benefits of stents, as well as their disadvantages, availability, and novel options of palliative management of oesophageal and gastro-oesophageal junction carcinoma.

\section{Address for correspondence}

Janusz Wlodarczyk MD, PhD, Department of Thoracic and Surgical Oncology, John Paul II Hospital, 80 Prądnicka St, $31-202$ Krakow, Poland, phone: +48 691893 853, e-mail: jr.wlodarczyk@gmail.com 

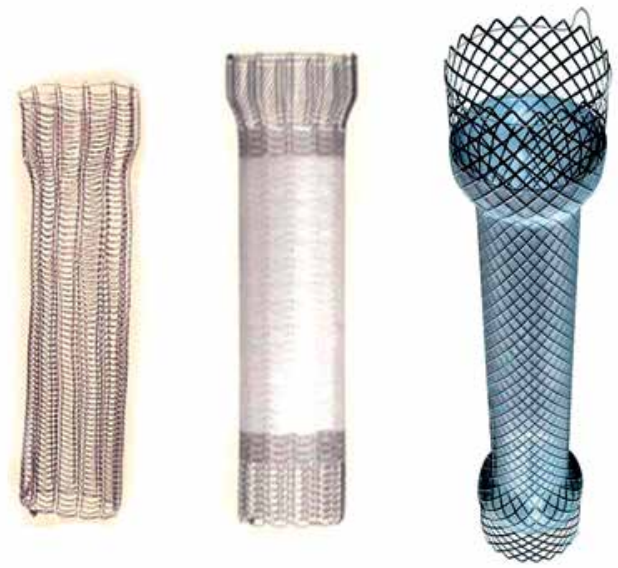

Photo 1. Uncovered and partially covered selfexpanding metal stents (PCSEMS) from left to right: Ultraflex (uncovered) (Boston Scientific) Ultraflex (partial covered) (Boston Scientific), Evolution (Cook)

\section{Stents}

Currently, various stents are commercially available in Europe, America and Asia, which differ in their structure, deployment system, required pre-dilatation, coverage, and preparation for introduction. In general, stents should be characterised by a thin wall, elasticity, easy application, and low complica- tion rate. Oesophageal stents (Photos 3 and 4) may be categorised as follows:

A. Depending on the coverage (Photos 1, 2):

1) partially covered self-expandable stents - e.g. Ultraflex, Esopha-Coil, Flamingo, Gianturco Z-stent, Evolution;

2) fully covered self-expandable stents - e.g. Alimaxx-E, Niti-S, SX-Ella, Wallflex, Polyflex.

B. Depending on the material used:

1) nitinol - e.g. Ultraflex, Esopha-Coil, Wallflex, Niti-S, Choo, Hanaroo, Evolution, Alimaxx-E;

2) steel - e.g. Gianturco Z-stent, Flamingo, Wallstent II;

3) plastic - e.g. Polyflex.

4) polydioxanone - e.g. Ella (Photo 3).

C. Depending on function:

1) with an anti-reflux valve - e.g. Ella, Dostent;

2) with an anti-migration mechanisms - e.g. Ali$\operatorname{maxx}$.

D. Depending on release:

1) distal - e.g. Ultraflex;

2) proximal - e.g. Ultraflex.

The introduction of self-expanding metallic stents (SEMS) resulted in the elimination of rigid prostheses, which were associated with high incidence of severe complications. Covered stents constitute the largest and most commonly used
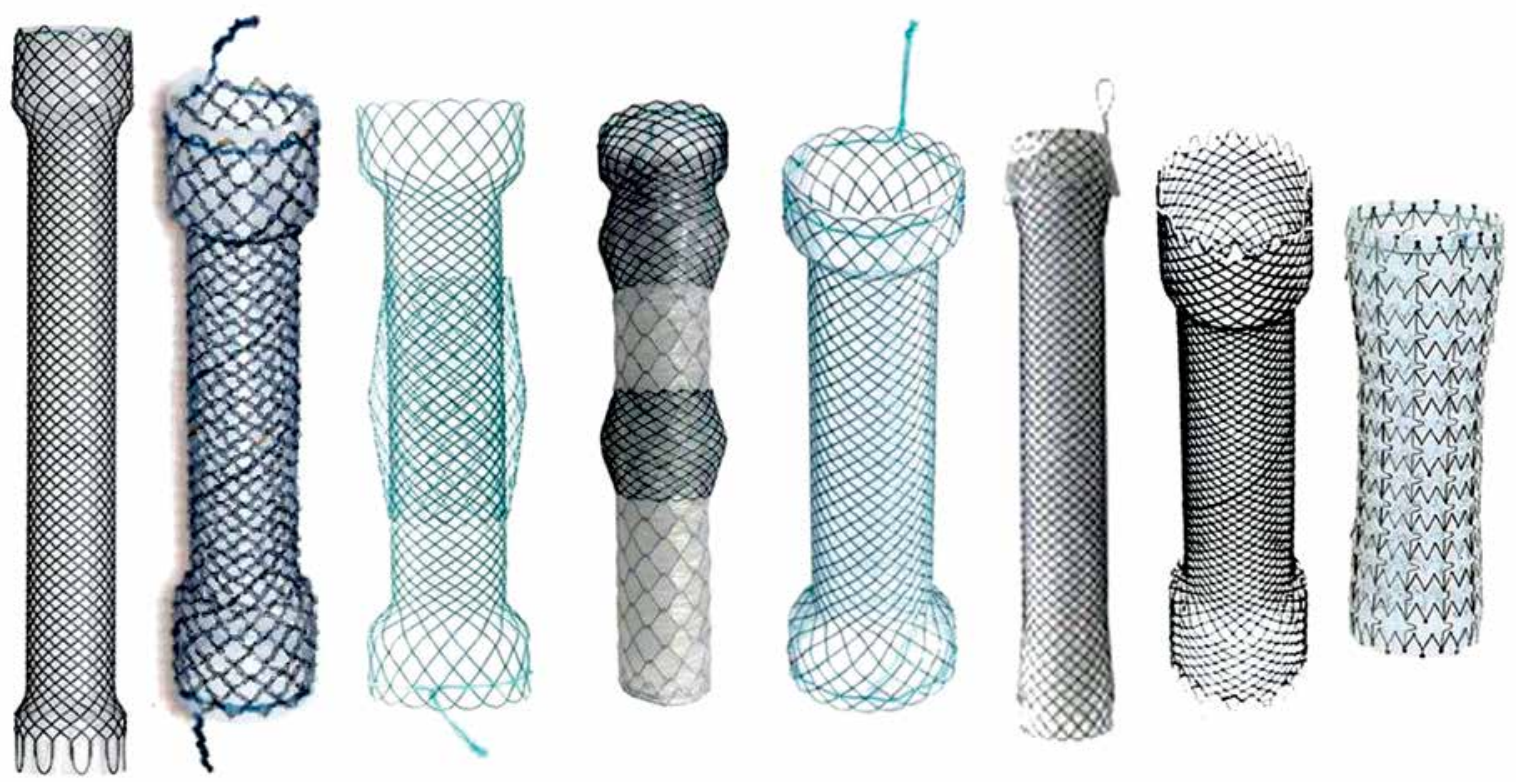

Photo 2. Fully covered self-expanding metal stents (FCSEMS) and partial covered self-expanding metal stents (PCSEMS) from left to right: Wallflex (Boston Scientific), Evolution (Cook), Niti-S double oesophageal stent (Taewoong), Niti-S Beta 2 (Taewoong) Niti-S S oesophageal stent (Taewoong), Flexella Plus (Ella), Evo - PCSEMS (Cook), Alimaxx ES (Endotek) 
group. While uncovered SEMS were characterised by neoplastic tissue ingrowth, very difficult or impossible removal and difficult repositioning after implantation, the partially covered SEMS are associated with a much lower rate of these complications. They are, however, not free of problems, such as hypertrophic granulation of the proximal or distal end, leading to occlusion, migration, and fistula development [13].

The introduction of fully covered self-expanding stents in 2001 did not solve all problems. These stents are characterised by difficult implantation, due to their plastic construction. They have to be introduced through a guide, which is rigid, approximately $10 \mathrm{~mm}$ in diameter, and not always arranged in a manner suited to the intended site of implantation. These stents are also characterised by a tendency for migration.

Absorbable stents are a relatively new alternative for patients with oesophageal carcinoma. These stents may be used in the preoperative period, since their functioning is limited by the absorption time of $\sim 12$ weeks. They are made of an absorbable material - PDS. Their potential advantage is based on the possibility of absorption, although implantation requires wide oesophageal patency restoration, which limits the use of absorbable stents.
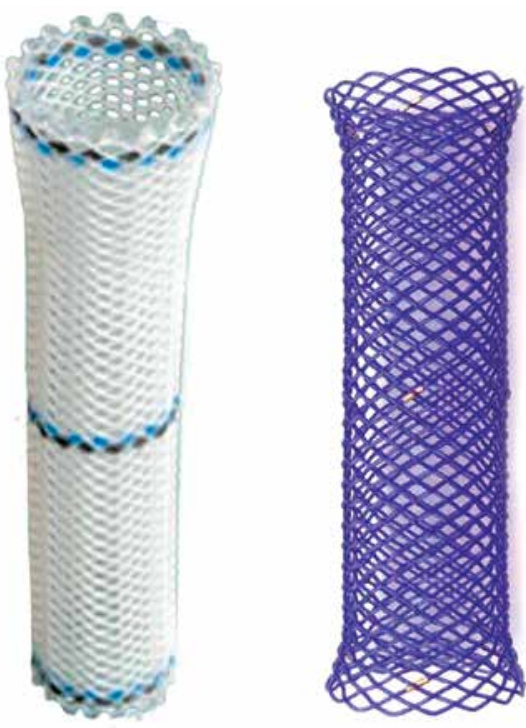

Photo 3. Fully covered plastic prosthesis on the left side: Polyflex (Boston Scientific) and SX Ella degradable (Ella) prosthesis on the right side for treatment of benign and malignant oesophageal stricture

An oesophagealstentmaybe applied afterneoplastic stricture dilatation (up to the diameter of $10 \mathrm{~mm}$ ). Commercially available oesophageal stents may be introduced under radiological or endoscopic con-

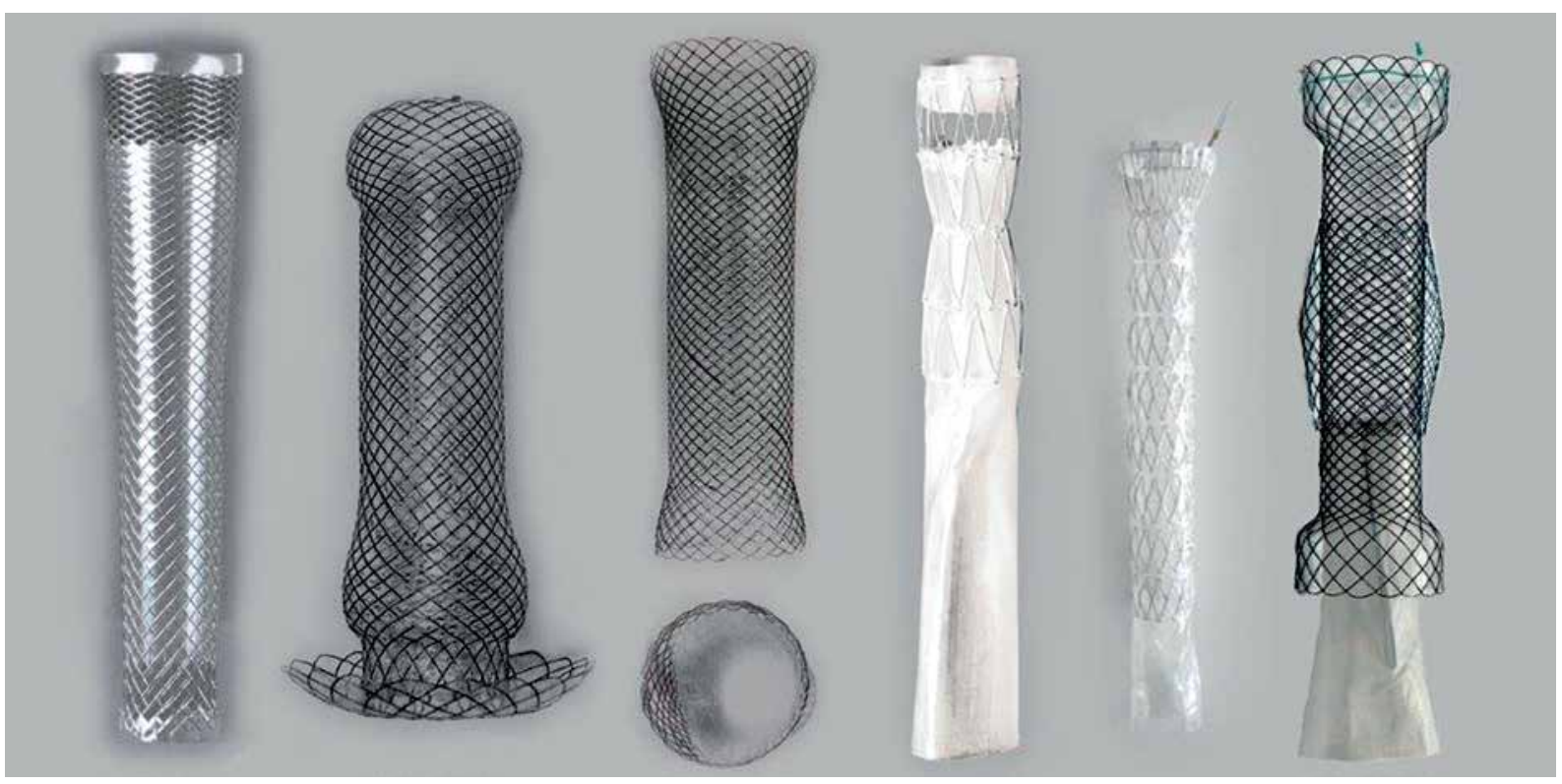

Photo 4. Types of prosthesis for oesophago-gastric junction cancer stenting, from left to right: Flamingo stent - PCSEMS (Boston Scientific), Cardia-Umbrella - FCSEMS (Micro-Tech), Cardia-Valve-stent - FCSEMS (Micro-Tech), Dua antireflux "wind sock" - PCSEMS (Cook), Boubella-E antireflux valve (FCSEMS) (Ella), Niti-S double anti-reflux valve (FCSEMS) (Taewoong) 
trol, and therefore are equipped with markers, easily identified on the fluoroscopy image. Endoscopic clips can also be used to mark the area of dilatation.

\section{Clinical evaluation}

Oesophageal stenting is the method of choice in palliative management, but specific types of stents may also be used in cases of benign strictures and iatrogenic oesophageal perforations with mediastinitis [14].

The main indications for palliative oesophageal stenting include:

- dysphagia due to the inoperable oesophageal cancer;

- oesophageal compression due to mediastinal diseases (Hodgkin's disease, non-Hodgkin's lymphoma, inoperable lung cancer);

- small cell lung cancer infiltrating the oesophagus;

- thyroid cancer.

Patients requiring stenting are usually diagnosed with grade III and IV dysphagia and significant weight loss. It should also be remembered that these patients may require bronchial tree stenting, due to the close anatomical relationship between the oesophagus and bronchial tree (trachea and main bronchus). Therefore, during the endoscopic examination, the bronchial tree should also be assessed, especially when the neoplastic infiltration is located $\sim 25 \mathrm{~cm}$ from the incision. In patients diagnosed with locally advanced cancer, compression of the left main bronchus and/or tracheal bifurcation may be observed, as well as oesophago-respiratory fistula. Deployment of the stent within the oesophagus may exacerbate compression of the airway and lead to acute asphyxia. Therefore, oesophageal stenting in such patients requires the preparation of the team to perform, if necessary, simultaneous bronchial tree stenting [15]. If this is anticipated on the basis of CT scan, airway stenting should be performed first.

\section{Oesophageal dilatation}

Patients with grade III and IV dysphagia require stricture dilatation before the stenting procedure. The dilatation technique in cases of oesophageal strictures varies among centres.

Generally, three methods of dilatation can be distinguished [16]:

1) mercury-filled rubber dilators - e.g. Maloney or Hurst;
2) guided polyvinyl dilators - e.g. Savary-Gilliard, Eder-Puestow, Celestin, Beuss, Biomed System American;

3) hydrostatic polyurethane balloons - e.g. TTS (through-the-scope), Rigiflex, Medi-Tech.

Mercury-filled rubber dilators are nowadays rarely used and have a mainly historical importance. They are most commonly employed in cases of short and medium-sized stricture dilatations. Wire-guided dilators are most commonly used. This is associated with their relative safety, 'tactile sensitivity' during the procedure, and low rate of complications.

Pneumatic balloon dilators are also very popular. The method is characterised by a low perforation rate. When using balloon dilators, there is no tactile control over stricture dilatation.

\section{Oesophageal stent characteristics}

Oesophageal stenting has been developing since the 1970s, when rigid stents were introduced by Wilson-Cook. Due to implantation difficulties and material quality, their use was associated with a high percentage of complications, especially oesophageal perforation, bronchial tree fistula formation, and a mortality rate of up to $10 \%$. They were subsequently replaced by steel wire prostheses, which had fewer complications, although tumour ingrowth was an important drawback. Nowadays, fully or partially covered prostheses are used. These are characterised by a low complication rate [17].

The ideal prosthesis should have the following characteristics:

- appropriate diameter enabling full oral nutrition without obstruction after meals;

- low risk of migration, granulation tissue stent overgrowth, bleeding, and fistula formation;

- flexibility;

- technical simplicity of implantation, reposition, and removal;

- low risk of regurgitation.

The Ultraflex stent (Boston Scientific, Natick, USA) is made of nitinol, and fully or partially covered. It is highly flexible. These stents are also available without covering. Depending on the model, they have either proximal or distal release systems and facilitate precise implantation without fluoroscopic guidance, under simple endoscopic control. After implantation, they shorten by up to $30 \%$. The new generation of these fully or partially covered stents are silicone-covered nitinol prostheses. In contrast to 
those mentioned above, they can be refolded if dilatation amounts to $75 \%$. This stent is equipped with 'progressive step flared ends', preventing migration.

Gianturco Z-stents (Cook, Winston Salem, USA) are partially covered steel-wire prostheses, available with an anti-reflux valve.

The Evolution stent (Cook, Winston Salem, USA) is a nitinol, partially covered prosthesis. The stent is distally dilated with recapture possibility, prior to full dilatation (in case of 50\% dilatation). The stent contains an inner and outer membrane, which is intended to prevent granulation tissue ingrowth and to facilitate food passage. It has an anti-migration mechanism in the form of uncoated flanges on both ends.

Alimaxx-E (Alveolus, Charlotte, NC, USA) is a fully silicone covered, nitinol stent. The prostheses are laser-cut from a nitinol tube, and have an anti-reflux mechanism in the form of 'fish scales'. Fluoroscopy is not required. An interesting solution was proposed in cases of gastro-oesophageal junction cancer stents the cardia umbrella stent. Due to its umbrella design, this nitinol, fully covered prosthesis has the ability to adjust to the cardia area, preventing displacement.

Niti-S (Taewong Medical, Seoul, Korea) is a 'double stent', with a non-covered external layer intended to prevent migration and a silicone-covered internal layer preventing granulation tissue ingrowth.

Choo-stent (M.I. Tech Medical, Seoul, Korea) is a nitinol, fully covered prosthesis, polyurethane-coated, distally released. An anti-reflux valve option is possible.

SX-Ella (Ella-CS, Hradec Kralove, Czech Republic) is a fully covered nitinol or steel prosthesis, distally released, with an anti-reflux valve and proximal pole ring preventing migration.

Biodegradable stents (Ella-CS, Hradec Kralove, Czech Republic) are non-covered prostheses made of PDS with a 12-week period of absorption. They are recommended during chemo-radiotherapy, prior to planned surgery, and in cases of benign lesions. The mechanism of implantation allows for multiple use. Prior to implantation, the stricture should be dilated to 12-14 Fr values; the rigidity of the guide and its location do not always allow for convenient stent dilatation.

\section{Oesophageal stenting results and complications}

The aim of stenting in patients with inoperable or unresectable oesophageal cancer is to obtain oesophageal patency and complete oral nutrition. The development of endoscopy and technological progress currently enable the use of a number of oesophageal stents. The main characteristics include: safety and simplicity of implantation, bioelasticity, shape memory deployment, matching the shape of the stricture, resistance to deformation, and biodegradability [18]. Currently, steel, nitinol, cobalt, and an absorbable PDS polymer are used.

The procedure lasts a relatively short time, approximately $30 \mathrm{~min}$, with a technical success rate reaching $100 \%$. It is recommended to cover with the stent $\sim 4 \mathrm{~cm}$ of the oesophagus above and below the stricture, although this is not always possible, especially in cases of proximal strictures [19]. Currently, with the fully covered plastic prostheses, stenting of the cervical oesophagus is also possible. Stent implantation is associated with low perioperative mortality ranging from 0 to $5 \%$, while 30 -day mortality ranges between $7 \%$ and $18 \%$ [20-25].

The stents that are currently used, despite relative good tolerance, are not free from side-effects and complications. One of the most common complications associated with stenting is granulation tissue overgrowth. Coverage with a polyurethane or silicone membrane protects from tumour ingrowth, but overgrowth beyond the ends of the stent and granulation tissue formation remain an issue. Granulation tissue is observed within two months after stent implantation in $47 \%$ of patients [26-30]. This problem, although rarely, is encountered also with fully covered plastic stents [31, 32]. The cause of granulation tissue overgrowth remains unknown. Stents of a diameter smaller than $20 \mathrm{~mm}$ overgrow much more slowly (SX Ella stent, Polyflex, Niti-S and Gianturco Z-stent) [33].

Another important complication associated with oesophageal stents is migration. It is usually observed in $20 \%$ of cases and it more often concerns fully covered plastic stents, as compared to those partially covered. Verschuur et al. demonstrated that Ultraflex stent migration was observed in $17 \%$ of patients, while Polyflex stent migration in $29 \%$. Additionally, stents with an anti-migration mechanism (SX Ella, Niti-S, Alimaxx) do not always effectively prevent this complication [24, 28].

Fistulas to the bronchial tree are late, life-threatening complications. They occur in $10 \%$ of patients after stenting. Ferreira et al. observed their occurrence in 7 of 126 patients, while Uitdehaag et al. 
observed them in 2 out of 4, after the use of SX Ella stents [29, 34, 35].

Bleeding after stenting is another life-threatening complication, and it reportedly occurs in 2-28\% of patients [34, 36, 37].

Other, less severe complications include chest pain, foreign body sensation, and regurgitation. When considering the above-mentioned stents, no evidence of superiority of any of the prostheses was observed [23].

\section{Gastro-oesophageal junction stenting}

Gastro-oesophageal junction cancer stenting, as compared to proximal oesophageal stenting, is characterised by certain peculiarities and a higher complication rate. Stent migration is the most common complication. It is associated with fixation of the proximal end of the stent only - its distal segment being located in the stomach. Such a location also favours bleeding after stent placement. Siersma et al. connected this with two factors. First, the free segment of the stent assumes a forced position, pressing against the posterior wall of the oesophagus, which leads to its damage, ulceration, and bleeding. Secondly, the forced position of the stent, determined by the anatomy of the angle between the oesophagus and cardia, leads to exacerbation of reflux and worse swallowing quality [38, 39]. Vakil et al., in a randomised study, observed migration of the stent placed across the cardia in $12 \%$ of cases [40].

It appears that the type of stent, especially its proximal diameter (flange diameter: Flamingo Wallstent - $30 \mathrm{~mm}$, Wallstent $\mathrm{II}-28 \mathrm{~mm}$ and Ultraflex - $28 \mathrm{~mm}$ ), may play an important role in preventing migration. However, other studies showed that a larger stent diameter led to an increased rate of perforations and bleeding [33, 41, 42].

Vakil et al. demonstrated migration in $12 \%$ of cases, while the overall complication rate was 30\%. Other most common complications include: fever, not necessarily associated with aspiration pneumonia, chest pain, granulation tissue overgrowth, food bolus obstruction, and perforation. No evidence of superiority of any of the stents was observed, when considering complications after stenting of the cardia $[38,43]$.

It is believed that adjuvant chemo- and/or radiotherapy may increase the proportion of complications. It should be remembered that dysphagia may persist in a subset of patients following proper stent implantation, due to peritoneal metastases causing mechanical obstruction.

\section{Quality of life}

Quality of life is one of the most important factors of effective palliative treatment. Among the many questionnaires, the EORTC QLQ-C30 protocol is most often used. With 30 questions, it assesses the physical and emotional functioning, grade of dysphagia, nausea, vomiting, gastric content regurgitation, pain, degree of anxiety, and depression. The assessment of dysphagia is the key element considering the quality of life in patients with oesophageal carcinoma [44, 45].

\section{Conclusions}

Oesophageal metallic stents remain the gold standard in the palliative treatment in advanced squamous cell carcinoma of the oesophagus. Partially and fully covered stents are highly useful and well accepted. New stent designs and evolution of materials have reduced complication rates after stenting and increased the effectiveness and safety of palliative therapy. It should be remembered that some patients require bilateral stenting of the oesophagus and bronchial tree.

\section{Conflict of interest}

The authors declare no conflict of interest.

\section{References}

1. Parkin DM, Bray F, Ferlay J, et al. Global cancer statistics 2002. Ca Cancer J Clin 2005; 55: 74-108.

2. Brown LM, Devesa SS, Chow WH. Incidence of adenocarcinoma of the esophagus among white Americans by sex, stage, and age. J Natl Cancer Inst 2008; 100: 1184-7.

3. Trivers KF, Sabatino SA, Stewart SL. Trends in esophageal cancer incidence by histology, United States, 1998-2003. Int J Cancer 2008; 123: 1422-8.

4. Bosetti C, Levi F, Ferlay J, et al. Trends in oesophageal cancer incidence and mortality in Europe. Int J Cancer 2008; 122: 1118-29.

5. Siegel R, Ma J, Zou Z, Jemal A. Cancer statistics, 2014. CA Cancer J Clin 2014; 64: 9-29.

6. Lambert R. Palliation of carcinoma of the esophagus: is there a hope for cure? Am J Gastroenterol 1994; 89: S27-40.

7. Maier A, Anegg U, Fell B, et al. The effect of photodynamic therapy in a multimodale. Lasers Surg Med 2000; 26: 461-6.

8. Ludwig D, Dehne A, Burmester E, et al. Treatment of unresectable carcinoma of the esophagus or the gastroesophageal 
junction by mesh stents or without radiochemiotherapy. Int J Oncol 1998; 13: 583-8.

9. Beynon J, Winston T, Thompson MH. Endoscopic insertion of Celestin tubes in carcinoma of the esophagus. Gut 1991; 84: 479-80.

10. Fugger R, Niederle B, Jantsch $H$, et al. Endoscopic tube implantation for the paliation of malignant esophageal stenosis. Endoscopy 1990; 22: 100-4.

11. Domschke W, Foerster EC, Matek W, et al. Self-expanding mesh stent for esophageal cancer stenosis. Endoscopy 1990; 22 134-6.

12. Song HY, Choi KC, Kwon HC, et al. Esophageal strictures: treatment with a new design of modified Giantturco stent. Work in progress. Radiology 1992; 184: 729-34.

13. Raijman I, Siddique I, Ajani J, Lynch P. Paliation of malignant dysphagia and fistulae with coated expandable metal stents: experience with 101 patients. Gastrointest Endosc 1998; 48: 179-82.

14. Safranek J, Geiger J, Vesely V, et al. Esophageal stents for less invasive treatment of mediastinitis. Videosurgery Miniinv 2014; 9: $1-5$.

15. Sihoe AD, Wan IP, Yim AP. Airway stenting for unresectable esophageal cancer. Surg Oncol 2014; 13: 17-25.

16. Hunter JG, Pellegrini CA. Surgery of the esophagus. Surg Clin N Am 1997; 77: 1202-3.

17. Schembre D. Advances in esophageal stenting: the evolution of fully covered stents for malignant and benign disease Adv Ther 2010; 27: 413-25.

18. Mijazawa T, Yamakido M, Ikeda S, et al. Implantation of ultraflex nitinol stents in malignant tracheobronchial stenoses. Chest 2000; 39: 1088-9.

19. National Comprehensiv Cancer Network Guidelines for the treaetment of esophagealcancer 2014. Available at: www.nccn. org/professionals/physcian_glsf_guidlines.asp\#site 2014.

20. McManus K, Khan I, McGuigan J. Self expanding oesophageal stents: strategies for re-intervention. Endoscopy 2001; 33: 601-4.

21. Wilkes EA, Jackson IM, Cole AT, et al. Insertion of expandlable metallic stents in esophageal cancer without fluoroscopy in safe and effective: a 5-year experience. Gastrointest Endosc 2007; 65: 923-9.

22. Verschuur EM, Homs MY, Steyerberg EW, et al. A new esophageal stent design (Niti-S stent) for the prevention of migration: a prospective study in 42 patients. Gastrointest Endosc 2006; 63: $134-40$

23. Burstow M, Kelly T, Panchani S, et al. Outcome of palliative esophageal stenting for malignant dysphagia: a retrospective analysis. Dis Esophagus 2009; 22: 519-25.

24. Conigliaro R, Battaglia G, Repici A, et al. Polyflex stents for malignant oesophageal and oesophago-gastric stricture: a prospective, multicenter study. Eur I Gastroenterol Hepatol 2007; 19: 195-203.

25. Ross WA, Alkassab F, Lynch PM, et al. Evolving role of self-expanding metal stents in the treatment of malignant dysphagia and fistulas. Gastrointest Endosc 2007; 65: 70-6.

26. Mayoral W, Fleischer D Salcedo J, et al. Nonmalignant obstruction is a common problem with metal stents in the treatment of esophageal cancer. Gastrointest Endosc 2000; 51: 556-9.
27. Homs MY, Steyerberg EW, Eijkenboom WM, et al. Single dose brachytherapy versus metal stent placement for the palliation of dysfagia from esophageal cancer: multicenter randomized trial. Lancet 2004; 364: 1497-504.

28. Conio M, Repici A, Battaglia G, et al. A randomized prospective comparison of self expandable plastic stents and partially covered self expandable metal stents in the palliation of malignant esophageal dysphagia. Am J Gastroenterol 2007; 102: 2667-77.

29. Uitdehaag MJ, Siersema PD, Spaander MC, et al. A new fully covered stent with antimigration properties for the palliation of malignant dysphagia: a prospective cohort study. Gastrointest Endosc 2010; 71: 600-5.

30. Verschuur EM, Homs MY, Steyerberg EW, et al. A new esophageal stent design (Niti-S stent) for the prevention of migration: a prospective study in 42 patients. Gastrointest Endosc 2006; 63: 134-40.

31. Sharma P, Kozarek R. Role of esophageal stents in benign and malignant disease. Am J Gastroenterol 2010; 105: 258-73.

32. Bethge N, Somer A, Gross U, et al. Human tissue responses to metal stents implanted in vivo for the palliation of malignant stenoses. Gastrointest Endosc 1996; 43: 596-602.

33. Verschuur EM, Steyerberg EW, Kuipers EJ, et al. Effect of stent size on complications and recurrent dysphagia in patients with esophageal or gastric cardia cancer. Gastrointestinal Endosc 2007; 65: 592-601.

34. Ferreira F, Bastos P, Ribeiro A, et al. A comparative study between fluoroscopic and endoscopic guidance in palliative esophageal stent placement Dis Esophagus 2012; 25: 608-13.

35. Lopes CV, Pesenti C, Bories E, et al. Self expiable metallic stents for palliative treatment of digestive cancer. Clin Gastroenterol 2008; 42: 991-6.

36. Qiu G, Tao Y, Du X, et al. The impact of prior radiotherapy on fatal complications after self-expandable metallic stents (SEMS) for malignant dysphagia due to esophageal carcinoma. Dis Esophagus 2013; 26: 175-81.

37. Choi SJ, Kim JH, Choi JW, et al. Fully covered, retrievable self-expanding metal stents (Niti-S) in palliation of malignant dysphagia: long-term results prospective study. Scand I Gastroenterol 2011; 46: 875-80.

38. Siersma PD, Marcon M, Vakil N. Metal stents of the distal esophagus and gastric cardia. Endoscopy 2003; 35: 79-85.

39. Spinelli P, Cerrai FG, Ciuffi M, et al. Endoscopic stent placement for cancer of the lower esophagus and gastric cardia. Gastrointest Endosc 1994; 40: 455-7.

40. Vakil N, Morris Al, Marcon N, et al. A prospective, randomized, controlled trial of covered expandable metal stents in the palliation of malignant esophageal obstruction at the gastroesophageal junction. Am J Gastroenterol 2001; 96: 1791-6.

41. Siersema PD, Hop WCJ, van Blankenstein M, et al. A new design metal stent (Flamingo stent) for palliation of malignant dysphagia: a prospective study. Gastrointest Endosc 2000; 51: 139-45.

42. Siersema PD, Hop WCJ, van Blankenstein M, et al. A comparison of 3 types of covered metal stents for the palliation of patients with caused by esophagogastric carcinoma: a prospective, randomized study. Gastrointest Endosc 2001; 54: 145-53. 
43. Sgourakis G, Gockel I, Radtke A, et al. The use of self-expanding stents in esophageal and gastroesophageal junction cancer palliation: a meta-analysis and meta-regression analysis of outcomes. Dig Dis Sci 2010; 55: 3018-30.

44. Blazeby JM. Measurement of outcome. Surg Oncol 2001; 10: 127-33.

45. Aaronson NK, Ahmedzai S, Bergman B, et al. The European Organization for Research and Treatmant of Cancer QLQ-30: a quality-of life instrument for use in international clinical trials in oncology. J Natl Cancer Inst 1993; 85: 365-76.

Received: 29.04.2015, accepted: 7.03.2016. 